\title{
The Structural Basis of the Difference in Sensitivity for PNGase F in the De-N-glycosylation of the Native Bovine Pancreatic Ribonucleases B and $\mathrm{BS}^{\dagger}$
}

\author{
Véronique Blanchard, ${ }^{\ddagger \S}$ Martin Frank, ${ }^{\star}$ Bas R. Leeflang, ${ }^{\ddagger}$ Rolf Boelens," and Johannis P. Kamerling,,$*$ \\ Bijvoet Center, Department of Bio-Organic Chemistry and Department of NMR Spectroscopy, Utrecht University, Padualaan 8, \\ NL-3584 CH Utrecht, The Netherlands
}

Received June 25, 2007; Revised Manuscript Received November 9, 2007

\begin{abstract}
In glycoanalysis protocols, $N$-glycans from glycoproteins are most frequently released with peptide- $N^{4}$-( $N$-acetyl- $\beta$-glucosaminyl)asparagine amidase $\mathrm{F}$ (PNGase F). As the enzyme is an amidase, it cleaves the $\mathrm{NH}-\mathrm{CO}$ linkage between the Asn side chain and the Asn-bound GlcNAc residue. Usually, the enzyme has a low activity, or is not active at all, on native glycoproteins. A typical example is native bovine pancreatic ribonuclease B (RNase B) with oligomannose-type $N$-glycans at Asn-34. However, native RNase BS, generated by subtilisin digestion of native RNase $B$, which comprises amino acid residues 21-124 of RNase B, is sensitive to PNGase F digestion. The same holds for carboxymethylated RNase $\mathrm{B}$ (RNase $\mathrm{B}^{\mathrm{cm}}$ ). In this study, NMR spectroscopy and molecular modeling have been used to explain the differences in PNGase F activity for native RNase B, native RNase BS, and RNase $\mathrm{B}^{\mathrm{cm}}$. NMR analysis combined with literature data clearly indicated that the $N$-glycan at Asn-34 is more mobile in RNase BS than in RNase B. MD simulations showed that the region around Asn-34 in RNase B is not very flexible, whereby the $\alpha$-helix of the amino acid residues 1-20 has a stabilizing effect. In RNase BS, the $\alpha$-helix formed by amino acid residues $23-32$ is significantly more flexible. Using these data, the possibilities for complex formation of both RNase B and RNase BS with PNGase F were studied, and a model for the RNase BS-PNGase F complex is proposed.
\end{abstract}

Ribonucleases catalyze the breakdown of $3^{\prime}, 5^{\prime}$-phosphodiester linkages of single-stranded RNA, when a pyrimidine ring is at the $3^{\prime}$-side of the broken bond (1). Bovine pancreatic ribonuclease (RNase) ${ }^{1}$ is intensively used as a model in protein chemistry, when studying folding, structure, and stability, as well as enzyme catalysis. This enzyme is present in large quantities in the forestomach of cows and digests the RNA produced by microorganisms. Bovine pancreatic RNase was one of the first proteins that could be

${ }^{\dagger}$ This research has been financially supported by the Council for Chemical Sciences of The Netherlands Organization for Scientific Research (CW-NWO).

* To whom correspondence should be addressed. E-mail: j.p.kamerling@uu.nl.

* Department of Bio-Organic Chemistry.

$\S$ Present address: Institute of Clinical Chemistry and Pathobiochemistry, Charité University, Charité Platz 1, D-10117 Berlin, Germany.

"Department of NMR Spectroscopy.

${ }^{1}$ Abbreviations: Asn, asparagine; Asp, aspartic acid; CAT, conformational analysis tools; Cys, cysteine; FPLC, fast protein liquid chromatography; GlcNAc, $N$-acetyl-D-glucosamine; His, histidine; HMBC, heteronuclear multiple-bond correlation; HPLC, high-performance liquid chromatography; HSQC, heteronuclear single-quantum coherence; MALDI-TOF MS, matrix-assisted laser desorption ionization time-of-flight mass spectrometry; Man, D-mannose; MD, molecular dynamics; MLEV, composite pulse devised by M. Levitt; NMR, nuclear magnetic resonance; NOESY, nuclear Overhauser effect spectroscopy; PBC, periodic boundary condition; PDB, Protein Data Bank; PME, particle mesh Ewald; PNGase F, peptide- $N^{4}$-( $N$-acetyl- $\beta$-glucosaminyl)asparagine amidase F; rmsd, root-mean-square deviation; RNase, bovine pancreatic ribonuclease; Ser, serine; TOCSY, total correlation spectroscopy. synthesized chemically (2), and its three-dimensional structure is well-known from early X-ray (3) and NMR (4-6) studies.

Bovine pancreatic RNase is composed of 124 amino acids; it has four disulfide bridges and a molecular mass of 13.7 $\mathrm{kDa}$. RNase denoted RNase A is not glycosylated, whereas RNase B bears an oligomannose-type $\mathrm{Man}_{5-9} \mathrm{GlcNAc}_{2}$ moiety at Asn-34. The $N$-glycan stabilizes the glycoprotein toward proteolytic and temperature degradation (7). Digestion of RNase B with subtilisin results in so-called S peptide (residues 1-20) and RNase BS (residues 21-124). It should be noted that RNase BS is unable to degrade RNA (8).

Peptide- $N^{4}$ - $(N$-acetyl- $\beta$-glucosaminyl)asparagine amidase F (EC 3.5.1.52), also named $N$-glycanase or PNGase F, isolated from Flavobacterium meningosepticum bacteria (9), is able to cleave the amide bond between the Asn side chain and the first GlcNAc residue of glycoproteins, thereby converting Asn into Asp. A prerequisite is that the GlcNAcAsn element be accessible to the PNGase F active site. Many misfolded and all unfolded and denatured glycoproteins allow the cleavage of their $N$-glycans by PNGase F $(10,11)$. However, PNGase F is generally inaccessible to glycosylation sites on proteins in their native state.

Previously, it has been demonstrated that native RNase B is resistant to PNGase F cleavage whereas native RNase BS is sensitive to it (12). To explain the difference in reactivity of PNGase F toward these two substrates, in this study, the environment around Asn-34 was investigated by NMR spectroscopy and molecular modeling. NMR spectroscopy was used to assess the level of reduced mobility of the 
$N$-glycan at Asn-34 in RNase B, carboxymethylated RNase $B$ (RNase $\mathrm{B}^{\mathrm{cm}}$ ), and RNase BS. The flexibility of RNase B and RNase BS was investigated by molecular dynamics simulations in explicit solvent, and a preliminary model of the RNase BS-PNGase F complex was constructed.

\section{EXPERIMENTAL PROCEDURES}

Purification of RNase B. RNase B (300 mg) (EC 3.1.27.5, Sigma Chemical Co., St. Louis, MO) was dissolved in 20 $\mathrm{mM}$ Tris-HCl buffer ( $\mathrm{pH} 7.5$ ) containing $0.3 \mathrm{M} \mathrm{NaCl}, 1 \mathrm{mM}$ $\mathrm{CaCl}_{2}, 1 \mathrm{mM} \mathrm{MnCl}$, and $0.02 \% \mathrm{NaN}_{3}$ (buffer A). For affinity purification, the solution was divided into 15 portions, and each portion was applied to a $3 \mathrm{~mL}$ ConA-Sepharose column, pre-equilibrated in the same buffer. After being washed, the column was eluted with $100 \mathrm{mM}$ methyl $\alpha$-Dmannopyranoside in buffer A. The RNase B-containing fraction was lyophilized, then desalted with a HiTrap column (Pharmacia FPLC system; five columns connected, $5 \times 5$ $\mathrm{mL}$; eluent, $10 \mathrm{mM} \mathrm{NH} \mathrm{HCO}_{3}$; UV detection, $280 \mathrm{~nm}$ ), and finally lyophilized three times.

The affinity-purified RNase B was further purified in portions of $8 \mathrm{mg}$ by cation-exchange chromatography on a Mono S column (HR5/5, Amersham Biosciences, Piscataway, $\mathrm{NJ}$ ). Elutions were performed over 20 min with a gradient of $250 \mathrm{mM} \mathrm{NaCl}$ in $\mathrm{NaH}_{2} \mathrm{PO}_{4} / \mathrm{Na}_{2} \mathrm{HPO}_{4}$ buffer $(\mathrm{pH}$ 6.4) at a flow rate of $1 \mathrm{~mL} / \mathrm{min}$ and monitored by UV absorbance at $280 \mathrm{~nm}$. For gradient details, see the relevant figure captions. The RNase B-containing fractions were lyophilized and desalted using $5 \mathrm{kDa}$ centrifugal concentrators, and finally, retentates were lyophilized.

Preparation and Isolation of RNase BS. RNase B (20 mg/ $\mathrm{mL}$ ), dissolved in $100 \mathrm{mM}$ Tris-HCl buffer at $\mathrm{pH} 8.0$ and 5 ${ }^{\circ} \mathrm{C}$, was digested with subtilisin (EC 3.4.21.62; Sigma Chemical Co.) $\left(10 \mu \mathrm{g} / \mathrm{mg}\right.$ of sample) for $24 \mathrm{~h}$ at $5{ }^{\circ} \mathrm{C}$. To quench the digestion, the solution was acidified to $\mathrm{pH} 2.5$ with $100 \mathrm{mM} \mathrm{HCl}$ and, after $1 \mathrm{~h}$, set to $\mathrm{pH} 6.4$ with 100 $\mathrm{mM} \mathrm{NaOH}$. The formed RNase BS (amino acid residues 21-124) and S peptide (amino acid residues 1-20) were separated from RNase B on a Mono S column in portions of $3 \mathrm{mg}$ using the conditions described above. After being desalted via $5 \mathrm{kDa}$ centrifugal concentrators, samples were dissolved in $10 \mathrm{mM}$ citrate/phosphate buffer (pH 4.6) (10 $\mathrm{mg} / \mathrm{mL}$ ), and RNase BS was obtained by ethanol precipitation followed by centrifugation at $5000 \mathrm{~g}$. This procedure was repeated two times to remove contaminating $S$ peptide.

For further purification, RNase BS was applied to a Vydac (Hesperia, CA) 214TP510 C4 column $(4.6 \mathrm{~mm} \times 250 \mathrm{~mm})$, making use of a Waters 600 HPLC system monitored by UV absorbance at $280 \mathrm{~nm}$. Elutions were performed at a flow rate of $1.5 \mathrm{~mL} / \mathrm{min}$ with a gradient of acetonitrile in aqueous trifluoroacetic acid. Buffer A consisted of 5\% acetonitrile in $0.1 \%$ aqueous trifluoroacetic acid and buffer $\mathrm{B}$ of $95 \%$ acetonitrile in $0.1 \%$ aqueous trifluoroacetic acid. The linear gradients were comprised of $10 \%$ B for $5 \mathrm{~min}$, followed by 10 to $70 \%$ B over $35 \mathrm{~min}$, then 70 to $100 \%$ B over the next $5 \mathrm{~min}$, and 100\% B for $5 \mathrm{~min}$ before returning to the initial conditions in $5 \mathrm{~min}$.

Reduction and Carboxymethylation of RNase B. RNase B (10 $\mathrm{mg}$ ) was reduced and $S$-carboxymethylated according to standard procedures (13). Briefly, the sample was dissolved in $5 \mathrm{~mL}$ of $1 \mathrm{M}$ Tris-HCl buffer ( $\mathrm{pH} 8.25$ ) containing
$6 \mathrm{M}$ guanidinium- $\mathrm{HCl}, 1 \mathrm{mM}$ EDTA, and $34 \mathrm{mM}$ dithiothreitol, and the solution was kept for $2 \mathrm{~h}$ at $37^{\circ} \mathrm{C}$. Then, iodoacetic acid ( $0.5 \mathrm{M}$ in $0.5 \mathrm{M} \mathrm{NaOH})$ was added to a final concentration of $68 \mathrm{mM}$, and the incubation was continued for $30 \mathrm{~min}$ in the dark. After the reaction had been quenched via addition of an excess of 2-mercaptoethanol, lowmolecular mass compounds were removed by using $5 \mathrm{kDa}$ centrifugal concentrators, and the retentate, containing RNase $\mathrm{B}^{\mathrm{cm}}$, was recovered and lyophilized. The chemical conversion was checked by $10 \%$ SDS-PAGE under reducing conditions.

Release of $\mathrm{N}$-Glycans with PNGase $F$. Glycoprotein samples were dissolved $(2 \mathrm{mg} / \mathrm{mL})$ in $20 \mathrm{mM} \mathrm{NaH} \mathrm{PO}_{4} /$ $\mathrm{Na}_{2} \mathrm{HPO}_{4}$ buffer (pH 7.2) and digested with peptide- $N^{4}-(N-$ acetyl- $\beta$-glucosaminyl)asparagine amidase $\mathrm{F}$ (PNGase F, EC 3.5.1.52; Roche Applied Science) (0.5 unit/mg of sample) for $24 \mathrm{~h}$ at $37^{\circ} \mathrm{C}$.

Matrix-Assisted Laser Desorption Ionization Time-ofFlight Mass Spectrometry. MALDI-TOF mass spectra were recorded on a Voyager-DE PRO mass spectrometer (Applied Biosystems) with the implemented delayed extraction technique, equipped with a $\mathrm{N}_{2}$ laser ( $337 \mathrm{~nm}, 3 \mathrm{~ns}$ pulse width). Spectra (positive-ion mode) were recorded in a linear mode at an accelerating voltage of $25 \mathrm{kV}$ using an extraction delay of $300 \mathrm{~ns}$. Samples $(0.5 \mu \mathrm{L})$ were mixed in a 1:1 ratio on the target with the matrix solution consisting of $\alpha$-cyano4-hydroxycinnaminic acid $(10 \mathrm{mg} / \mathrm{mL})$ dissolved in an acetonitrile/water/trifluoroacetic acid mixture (50:49.7:0.3, $\mathrm{v} / \mathrm{v})$.

NMR Spectroscopy. NMR spectra of natural abundance RNase samples ( $\mathrm{pH} 4.6$ ) were recorded on 500, 700, and $900 \mathrm{MHz}$ Bruker spectrometers, and on a $600 \mathrm{MHz}$ Bruker spectrometer equipped with a cryoprobe at probe temperatures of $293 \mathrm{~K}$ for protein assignments and $308 \mathrm{~K}$ for carbohydrate assignments. Lyophilized glycoproteins $(\sim 20$ $\mathrm{mg}$ ) were dissolved in $500 \mu \mathrm{L}$ of $\mathrm{D}_{2} \mathrm{O}$ (99.9\%; Cambridge Isotope Laboratories Inc.) or a 9:1 (v/v) $\mathrm{H}_{2} \mathrm{O} / \mathrm{D}_{2} \mathrm{O}$ mixture. Chemical shifts were referenced to internal acetone $(\delta 2.225)$ for ${ }^{1} \mathrm{H}$ and to the $\alpha$-anomeric signal of external $\left[1-{ }^{13} \mathrm{C}\right] \mathrm{glu}-$ cose $\left(\delta_{\mathrm{C}-1} 92.9\right)$ for ${ }^{13} \mathrm{C}$. Two-dimensional (2D) TOCSY spectra were recorded using MLEV-17 mixing sequences of 50-200 ms. 2D NOESY spectra were recorded with mixing times of 80-250 ms. The spectra were recorded with 16 scans and $512 \times 2048$ points. A natural abundance ${ }^{15} \mathrm{~N}-{ }^{1} \mathrm{H}$ HSQC spectrum was obtained with $1024 \times 256$ points and 800 scans. ${ }^{13} \mathrm{C}-{ }^{1} \mathrm{H}$ HSQC and ${ }^{13} \mathrm{C}-{ }^{1} \mathrm{H}$ HMBC spectra were obtained with $512 \times 1024$ points and 16 and 512 scans, respectively. NMR data sets were processed using in-house developed software (J. A. van Kuik, Bijvoet Center, Department of Bio-Organic Chemistry, Utrecht University) with zero filling, a $\pi / 2$-shifted sine bell window function for $t_{1}$, a $\pi / 2$-shifted squared sine bell window function for $t_{2}$, and a seventh-order polynomial baseline correction in both dimensions when necessary.

Molecular Dynamics Simulations of RNase B and RNase $B S$ in Solvent. X-ray coordinates for RNase A (3) were retrieved from the Protein Data Bank (14) (PDB entry 3RN3, $1.45 \AA$ resolution). The heptasaccharide $\mathrm{Man}_{5} \mathrm{GlcNAc}_{2}$ was built separately with the LEAP module of the AMBER package (15) using the GLYCAM04 building blocks. The attachment of the carbohydrate to Asn-34 of the protein was performed using Conformational Analysis Tools (CAT) (16). The torsion $\mathrm{C}_{1}-\mathrm{N}-\mathrm{C}_{\gamma}-\mathrm{C}_{\beta}$ angle was set to $180^{\circ}$; the 


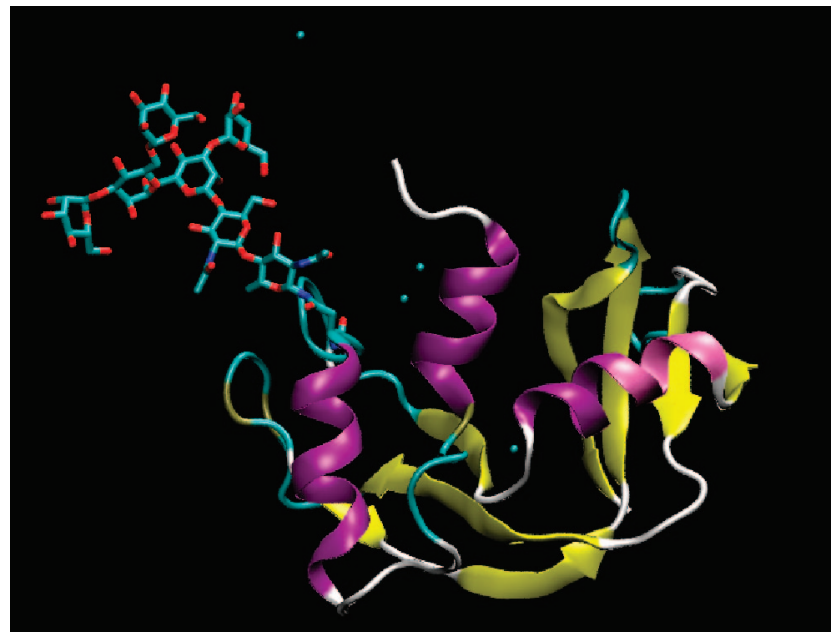

FIGURE 1: Structure of RNase B, built as described in Experimental Procedures.

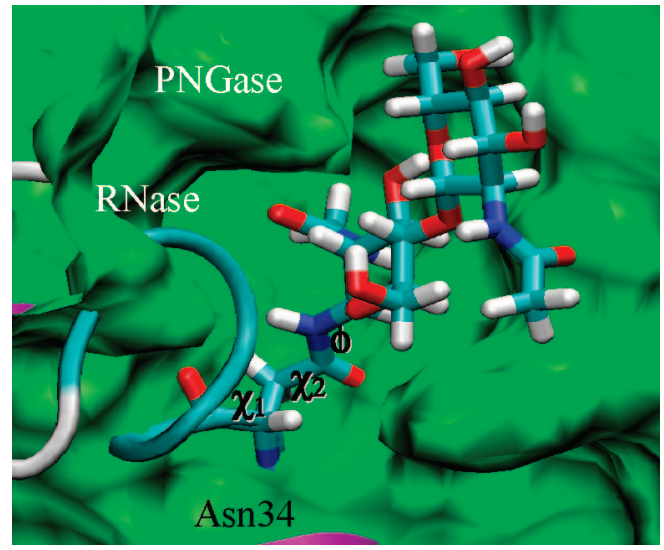

FIGURE 2: Torsion angles of interest $\left(\chi_{1}, \chi_{2}\right.$, and $\left.\varphi\right)$ occurring at Asn-34 in RNase B.

$\mathrm{O}_{5}-\mathrm{C}_{1}-\mathrm{N}-\mathrm{C}_{\gamma}$ angle was varied to a favorable position where no sterical overlap with any protein heavy atom occurred, and the NAc group of the Asn-bound GlcNAc (GlcNAc-1) was exposed to the solvent. On the basis of the crystal structure of PNGase F (PDB entry 1PNF), it is known that the NAc group of GlcNAc-1 binds into a pocket of the active site. Therefore, the solvent exposure of the NAc group is a precondition for binding to PNGase F. From this initial structure of the glycoprotein (hereafter termed RNase B), the trimmed version (RNase BS) was created by deleting residues 1 to 20 directly in the PDB file. Both files were further processed as follows. All His residues were assumed to be neutral and were protonated at the $\epsilon$ position. Cys $\mathrm{S}-\mathrm{S}$ bonds were created between the 26-84, 40-95, 58-110, and 65-72 residue pairs. Hydrogen atoms were added to the protein using LEAP. Four chlorine ions were added to counterbalance the overall positive charge of the system (Figure 1). For periodic boundary condition (PBC) simulations, the system was solvated in a box of TIP3P water with approximate dimensions of $79 \AA \times 55 \AA \times 64 \AA$ (the boxes contained 6391 and 6444 water molecules, respectively).

The molecular dynamics (MD) simulations were performed with the all-atom AMBER force field using the PARM99 parameters for proteins augmented with GLYCAM (17) parameters (version 04j) for oligosaccharides. Partial atomic charges for the carbohydrate and the protein were used as provided by the AMBER/GLYCAM prep files. The

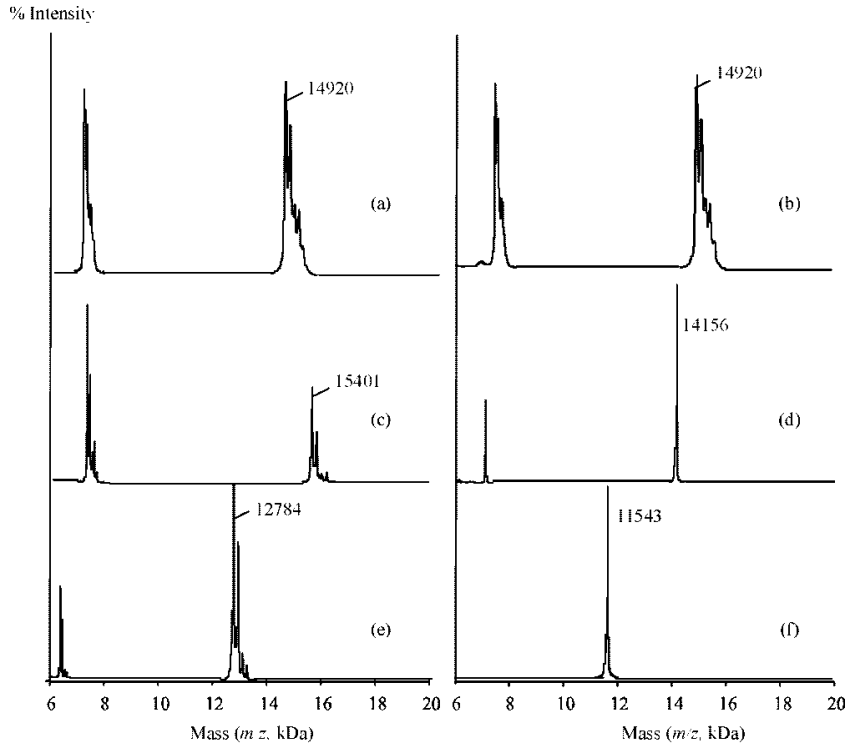

FIGURE 3: MALDI-TOF mass spectra recorded in positive-ion mode: (a) RNase B, (b) RNase B treated with PNGase F, (c) RNase B ${ }^{\mathrm{cm}}$, (d) RNase $\mathrm{B}^{\mathrm{cm}}$ treated with PNGase F, (e) RNase BS, and (f) RNase BS treated with PNGase F.

MD simulations were carried out by using the SANDER module and were performed using periodic boundary conditions and the particle mesh Ewald (PME) approach to account for long-range electrostatic effects. A $10 \AA$ A cutoff was used for calculating nonbonded interactions; $1-4$ electrostatics and nonbonded interactions were scaled by the default values of $1 / 1.2$ and $1 / 2.0$, respectively. Potentially unfavorable contacts in the initial structure were removed by 2500 cycles of energy minimization; 1000 cycles of steepest descent were followed by 1500 steps of conjugate gradient. Equilibration of the system was carried out as follows. After energy minimization, the temperature of the system was increased from 0 to $300 \mathrm{~K}$ over $20 \mathrm{ps}$ by coupling the system to a heat bath with a time constant of 1 ps using a weak-coupling algorithm $(18)(\mathrm{ntt}=1)$ while keeping the volume constant. The pressure was adjusted by isotropic position scaling to 1 bar (pressure relaxation time $=2 \mathrm{ps}$ ) and the water density to $1.01 \mathrm{~g} / \mathrm{cm}^{3}$ during the next $80 \mathrm{ps}$ of the equilibration period. Position restraints were applied during the whole equilibration period to all protein residues using a force constant of $500 \mathrm{kcal} / \mathrm{mol}$.

Production dynamics of $5 \mathrm{~ns}$ were performed at $300 \mathrm{~K}$ using a 2 fs time step, with the SHAKE algorithm applied to all hydrogen-containing bonds. For the PME simulation, the AMBER default options were used. During the MD simulation, snapshots of the coordinates were taken every picosecond. The resulting 5000 snapshots were analyzed with CAT (16).

rmsd values of protein backbone atoms were calculated after the backbone atoms of residues 40-120 had been superpositioned. This has been done to weight the rmsd values toward showing the relative movement of residues 1-39 more clearly. The average rmsd values per residue have been output to the column of the PDB file format normally used to store the crystallographic $\beta$ values. In this way, the "rmsd per residue" analysis could be displayed as a color code on the protein structure using VMD (19). The analysis of the stability of secondary structure motifs during the MD simulation has been performed using DSSP (20) interfaced 


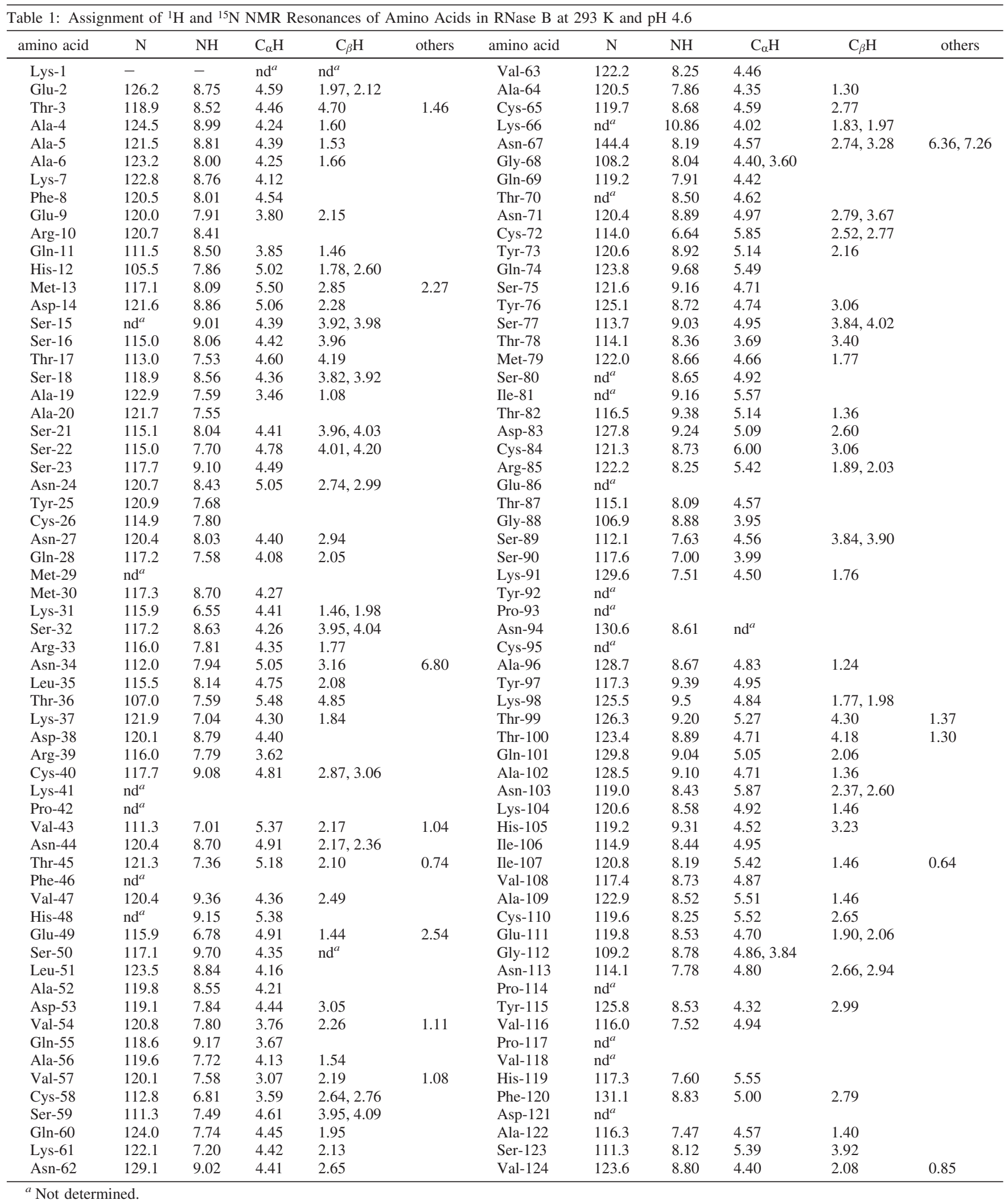

with CAT. Secondary structure analysis has been performed for all 5000 snapshots and the relative probability for a residue to be part of a motive calculated. Igor Pro (www. wavemetrics.com) has been used to generate the scientific plots.

Building a Model of the RNase BS-PNGase F Complex. The crystal structure of PNGase F (PDB entry 1PNF) contains $N, N^{\prime}$-diacetylchitobiose in the active site, so the starting structure of the complex of RNase with PNGase F was built by simply superimposing the $\operatorname{GlcNAc}(\beta 1-4)$ GlcNAc fragments connected to RNase B or BS and included in PNGase F. In the resulting structures, a significant number of atoms overlapped between the two proteins. Simple minimization was not possible due to crossing bonds. Therefore, the orientation of the disaccharide was optimized using systematic search methods so that a minimum of atoms 


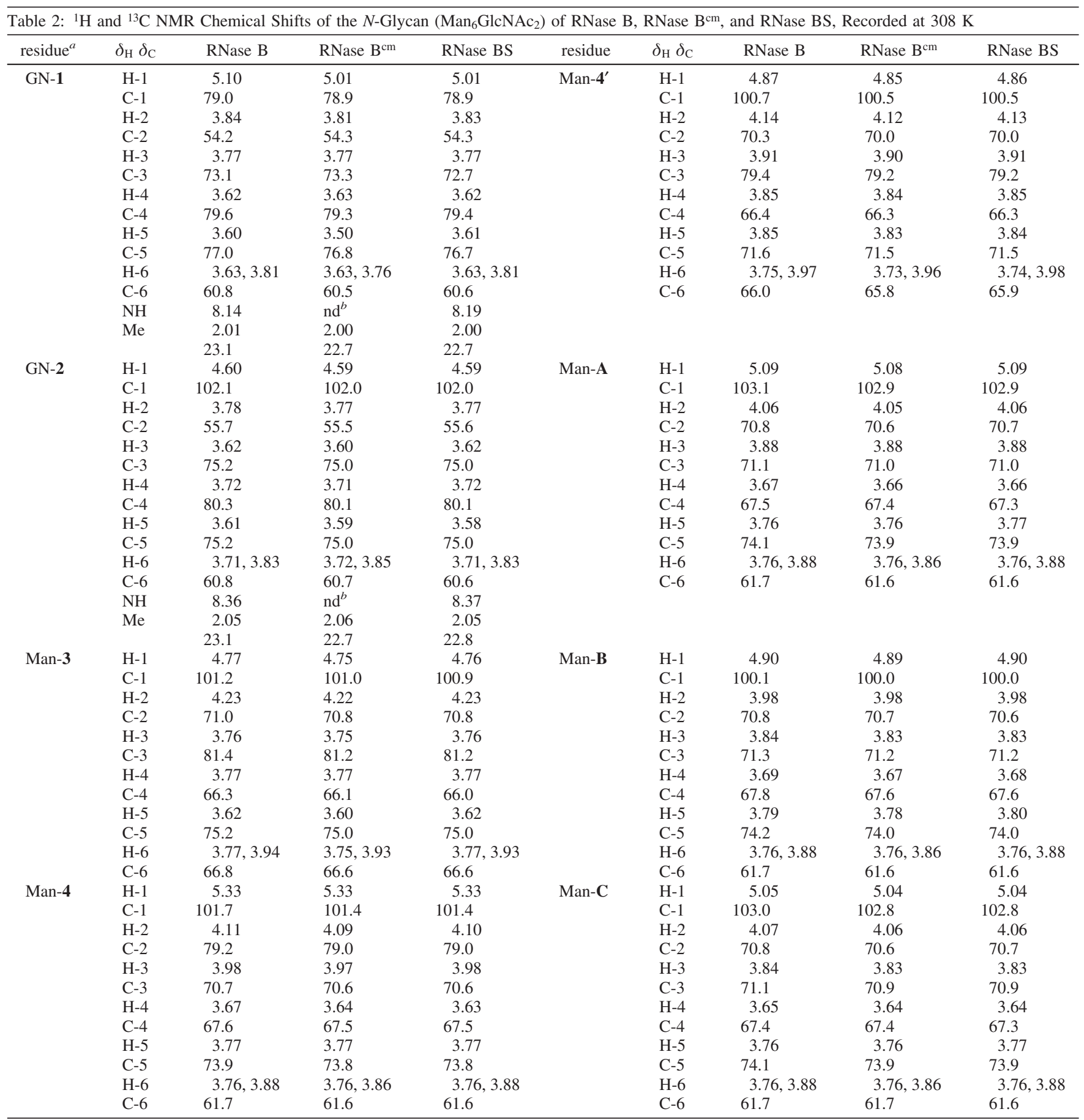

${ }^{a} \mathrm{GN}, \mathrm{N}$-acetylglucosamine (GlcNAc); Man, mannose. ${ }^{b}$ Not determined.

overlap between the two proteins. Conformational Analysis Tools (CAT) has been used to carry out an exhaustive conformational search by systematically varying the torsion angles $\chi_{1}$ and $\chi_{2}$ of Asn-34 and $\varphi_{\mathrm{N}}$ (Figure 2) in steps of $20^{\circ}$. The torsion $\Psi_{\mathrm{N}}$ was kept in a trans orientation. In this way, 5832 orientations were generated and evaluated. The system energy, calculated by using a force field, could not be used as a measure for optimal orientation, since in all orientations atom overlapping occurred and the energy was therefore always undefined (unlimited). Therefore, the number of atom overlaps was used as a measure. An overlap between two atoms was present when the interatomic distance was lower than the sum of the van der Waals radii. Only heavy atoms were considered in the analysis. Because the goal of the systematic search was to optimize the relative orientation of the two proteins, the $N$-glycan of RNase B or BS was truncated to the disaccharide $N, N^{\prime}$-diacetylchitobiose. The torsion angles used to describe the orientation of the GlcNAc-Asn linkage are defined as follows: $\chi_{1}=\mathrm{N}-\mathrm{C}_{\alpha}-$ $\mathrm{C}_{\beta}-\mathrm{C}_{\gamma}, \chi_{2}=\mathrm{C}_{\alpha}-\mathrm{C}_{\beta}-\mathrm{C}_{\gamma}-\mathrm{N}, \Psi_{\mathrm{N}}=\mathrm{C}_{\beta}-\mathrm{C}_{\gamma}-\mathrm{N}-\mathrm{C}_{1}$, and $\varphi_{\mathrm{N}}$ $=\mathrm{C}_{\gamma}-\mathrm{N}-\mathrm{C}_{1}-\mathrm{O}_{5}$.

To construct models with the full $\mathrm{N}$-glycan attached, a conformational analysis for $\mathrm{Man}_{5} \mathrm{GlcNAc}_{2}$ based on MD simulations in explicit solvent has been performed, and two representative conformations with a $g g$ and $g t$ orientation of $\omega$ in the (1-6) linkage of GlcNAc-1 have been derived. The conformational properties of the various linkages are similar to those described in ref 21 . The two conformations of 
$\mathrm{Man}_{5} \mathrm{GlcNAc}_{2}$ were attached to the best models of the complex in orientations $\mathbf{1}$ and $\mathbf{2}$ (see Results) by overlaying the $\mathrm{GlcNAc}_{2}$ fragments to check whether the full glycan can be accommodated.

\section{RESULTS}

Preparation of RNase B, RNase BS, and RNase $B^{c m}$. To remove contaminating RNase A, commercial RNase B was purified by ConA-Sepharose chromatography. The glycoprotein-containing fraction, eluted with methyl $\alpha$-D-mannopyranoside, was subjected to Mono $\mathrm{S}$ cation-exchange chromatography, yielding two subfractions named R1 and R2. Fraction R1 [RNase B, deamidated at Asn-67 (22); Asn $\rightarrow$ Asp] eluted around $160 \mathrm{mM} \mathrm{NaCl}$, and fraction $\mathbf{R 2}$ (intact RNase B) eluted around $175 \mathrm{mM} \mathrm{NaCl}$. The identity of intact RNase B was confirmed by NMR spectroscopy using NOESY measurements. A cross-peak was observed between the amide protons of the side chain of Asn-67 at $\delta 6.35 /$ 7.35 (data not shown).

To prepare RNase BS, purified intact RNase B (R2) was treated with subtilisin, and the digest was subjected to Mono S cation-exchange chromatography, yielding two subfractions, R2.1 and R2.2. Analysis by MALDI-TOF MS revealed that R2.1 corresponded to RNase B and R2.2 to RNase BS and $\mathrm{S}$ peptide (data not shown). To remove residual $\mathrm{S}$ peptide, fraction $\mathbf{R 2 . 2}$ was subjected to three ethanol precipitations, and the resulting residue was fractionated by RP-HPLC on a Vydac C4 column, yielding two subfractions named R2.2a and R2.2b. Both fractions were analyzed by MALDI-TOF MS, showing that fraction R2.2a corresponded to $\mathrm{S}$ peptide and fraction $\mathbf{R} 2.2 \mathrm{~b}$ to RNase $\mathrm{BS}$.

RNase $B^{\mathrm{cm}}$, being an unfolded form of RNase $B$, was prepared by reduction and carboxymethylation of RNase B.

PNGase F Digestion of RNase B, RNase BS, and RNase $B^{c m}$. To confirm the previously reported resistance and/or sensitivity for RNase B and RNase BS (12), PNGase F digestions of native RNase B (R2), native RNase BS (R2.2b), and unfolded RNase $\mathrm{B}^{\mathrm{cm}}$ were performed. The molecular masses of the substrates and the resulting products were verified by MALDI-TOF MS. As seen in panels a and b of Figure 3 , the $N$-glycan of RNase B was not cleaved by PNGase F (theoretical mass, $14921 \mathrm{Da}$; found, $14920 \mathrm{Da}$ ), indicating that the glycan is not accessible to the enzyme. On the other hand, PNGase F treatment of RNase BS (Figure 3e,f; theoretical mass of RNase BS, 12774 Da; found, 12784 $\mathrm{Da}$; theoretical mass of N-deglycosylated RNase BS, 11534 $\mathrm{Da}$; found, $11543 \mathrm{Da}$ ) and RNase $\mathrm{B}^{\mathrm{cm}}$ (Figure 3c,d; theoretical mass of RNase $\mathrm{B}^{\mathrm{cm}}, 15394 \mathrm{Da}$; found, $15401 \mathrm{Da}$; theoretical mass of N-deglycosylated RNase B ${ }^{\mathrm{cm}}, 14146 \mathrm{Da}$; found, $14156 \mathrm{Da}$ ) resulted in a complete removal of the carbohydrate moiety at Asn-34, indicating a structural change around Asn-34 when compared to RNase B. It should be noted that for RNase BS the amino acid numbering of RNase B is kept.

NMR Spectroscopy of RNase B (protein and glycan), RNase BS (glycan), and RNaseB ${ }^{c m}$ (glycan). The glycosylation pattern of RNase $B$ comprises oligomannose-type $\mathrm{N}$-glycans ranging from $\mathrm{Man}_{5} \mathrm{GlcNAc}_{2}$ to $\mathrm{Man}_{9} \mathrm{GlcNAc}_{2}$ : $53.5 \% \operatorname{Man}_{5} \mathrm{GlcNAc}_{2}, 22 \% \mathrm{Man}_{6} \mathrm{GlcNAc}_{2}, 6.6 \% \mathrm{Man}_{7^{-}}$ $\mathrm{GlcNAc}_{2}, 13.2 \% \mathrm{Man}_{8} \mathrm{GlcNAc}_{2}$, and 4.7\% $\mathrm{Man}_{9} \mathrm{GlcNAc}_{2}$ (23). These five $N$-glycans behave in the same way toward
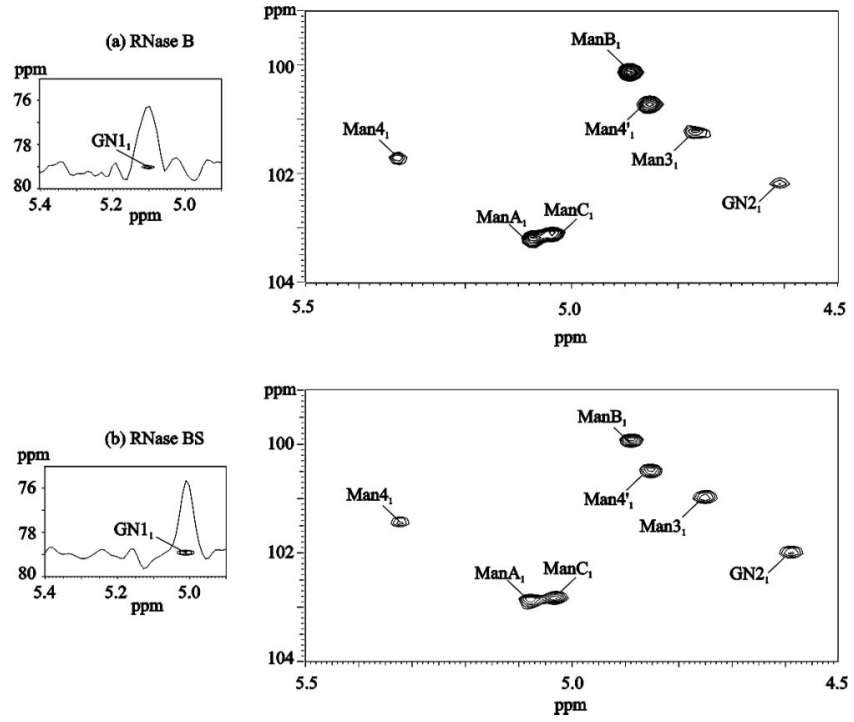

Figure 4: 700-MHz ${ }^{13} \mathrm{C}-{ }^{1} \mathrm{H}$ HSQC spectra (anomeric regions only) of the glycan at Asn-34 in (a) RNase B and (b) RNase BS, recorded at $308 \mathrm{~K}$ in $\mathrm{D}_{2} \mathrm{O}$. Man, mannose; GN, GlcNAc. Line widths are also shown for the GlcNAc-1 residue.

PNGase F digestion. Man ${ }_{6} \mathrm{GlcNAc}_{2}$ differs from $\mathrm{Man}_{5^{-}}$ $\mathrm{GlcNAc}_{2}$ by an ( $\left.\alpha 1-2\right)$-linked Man-C extension at Man-4. This means that Man-4 H-1 shifts from $\delta 5.09$ (in $\mathrm{Man}_{5} \mathrm{GlcNAc}_{2}$ ) to $\delta 5.33$ (in $\mathrm{Man}_{6} \mathrm{GlcNAc}_{2}$ ). The Man-4 residue in $\mathrm{Man}_{6} \mathrm{GlcNAc}_{2}$ is easily assigned in all the spectra that have been recorded, but this was not the case for the Man-4 residue in Man ${ }_{5} \mathrm{GlcNAc}_{2}$ because Man-4 H-1 overlaps with both Man-A H-1 and GlcNAc-1 H-1 in RNase B. To simplify the assignments, only the $\mathrm{Man}_{6} \mathrm{GlcNAc}_{2}$ structure was taken into account. The ${ }^{1} \mathrm{H}$ NMR signals of $\mathrm{Man}_{7-9}$ $\mathrm{GlcNAc}_{2}$ in the RNase samples were in general too weak to be unambiguously assigned.

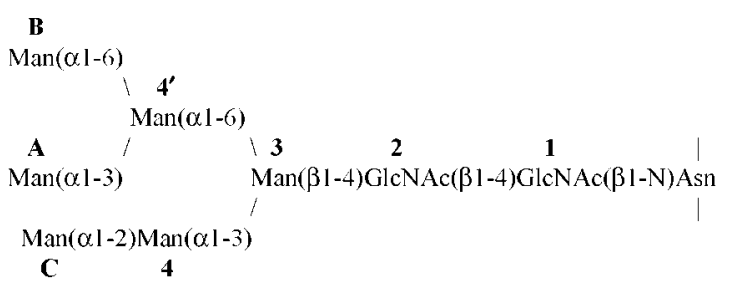

2D TOCSY, 2D NOESY, and ${ }^{15} \mathrm{~N}-{ }^{1} \mathrm{H}$ HSQC spectra of RNase B were checked against previously reported data for RNase A (4, 5). Small differences in chemical shifts were observed due to the $\mathrm{N}$-glycosylation in RNase $\mathrm{B}$, and probably also to different sample preparations (temperature and $\mathrm{pH}$ ). Therefore, all assignments were validated on their own (Table 1). The side chain of Asn-67 could be assigned, thereby clearly indicating the integrity of RNase B.

The ${ }^{1} \mathrm{H}$ and ${ }^{13} \mathrm{C}$ chemical shifts of $\mathrm{Man}_{6} \mathrm{GlcNAc}_{2}$ in RNase B were assigned by 2D TOCSY (50-200 ms), 2D NOESY, ${ }^{13} \mathrm{C}-{ }^{1} \mathrm{H}$ HSQC, and ${ }^{13} \mathrm{C}-{ }^{1} \mathrm{H}$ HMBC spectroscopy and are presented in Table 2. Starting points for these assignments formed the H-1 signals of the six Man and two GlcNAc residues, as previously reported for free oligosaccharides, glycopeptides, and glycoproteins (23-25); Figure 4a shows the anomeric region of the ${ }^{13} \mathrm{C}-{ }^{1} \mathrm{H}$ HSQC spectrum of RNase B. Comparison of the TOCSY spectra with increasing mixing times allowed the assignment of the sequential order of the chemical shifts belonging to one single spin system. As seen 


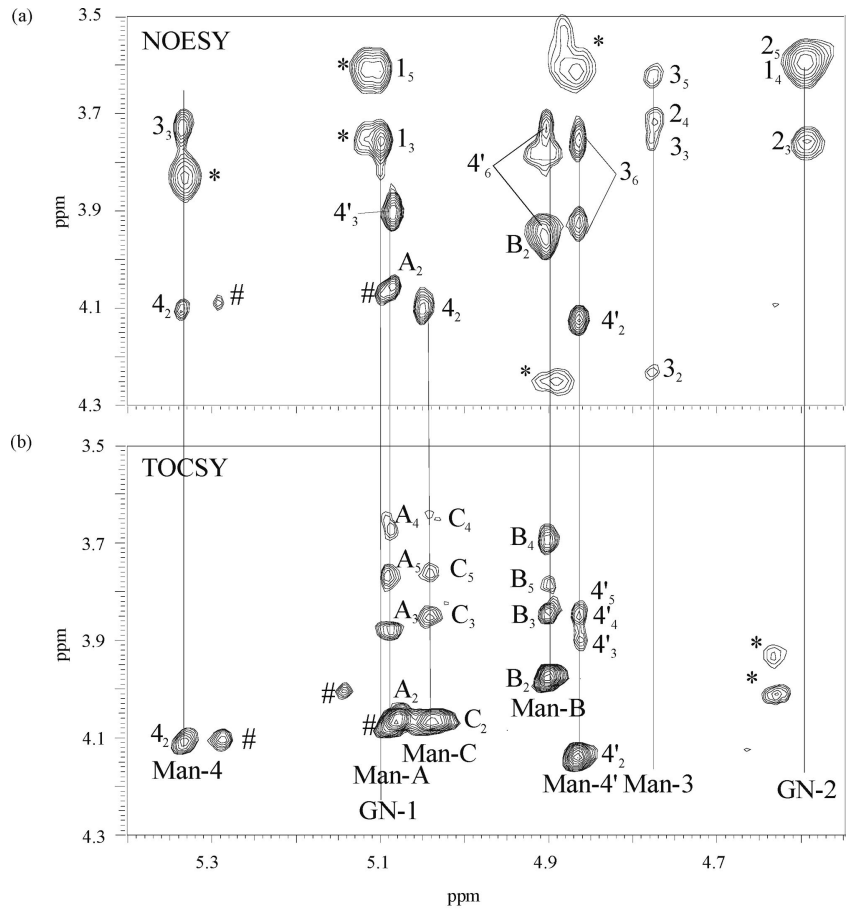

FIGURE 5: (a) 500-MHz 2D NOESY spectrum (mixing time of 80 $\mathrm{ms}$ ) and (b) 500-MHz 2D TOCSY spectrum (mixing time of 200 $\mathrm{ms}$ ) of the glycan at Asn-34 in RNase B, recorded at $308 \mathrm{~K}$ in $\mathrm{D}_{2} \mathrm{O}$. The number sign indicates cross-peaks corresponding to $\mathrm{Man}_{5,7-9} \mathrm{GlcNAc}_{2}$ structures in RNase B. Asterisks indicate RNase B protein cross-peaks. Man, mannose; GN, GlcNAc.

in the TOCSY spectrum (mixing time of $200 \mathrm{~ms}$ ) in Figure $5 \mathrm{~b}$, the Man- $\mathrm{C} \mathrm{H}-1$ track $(\delta 5.05)$ showed cross-peaks with

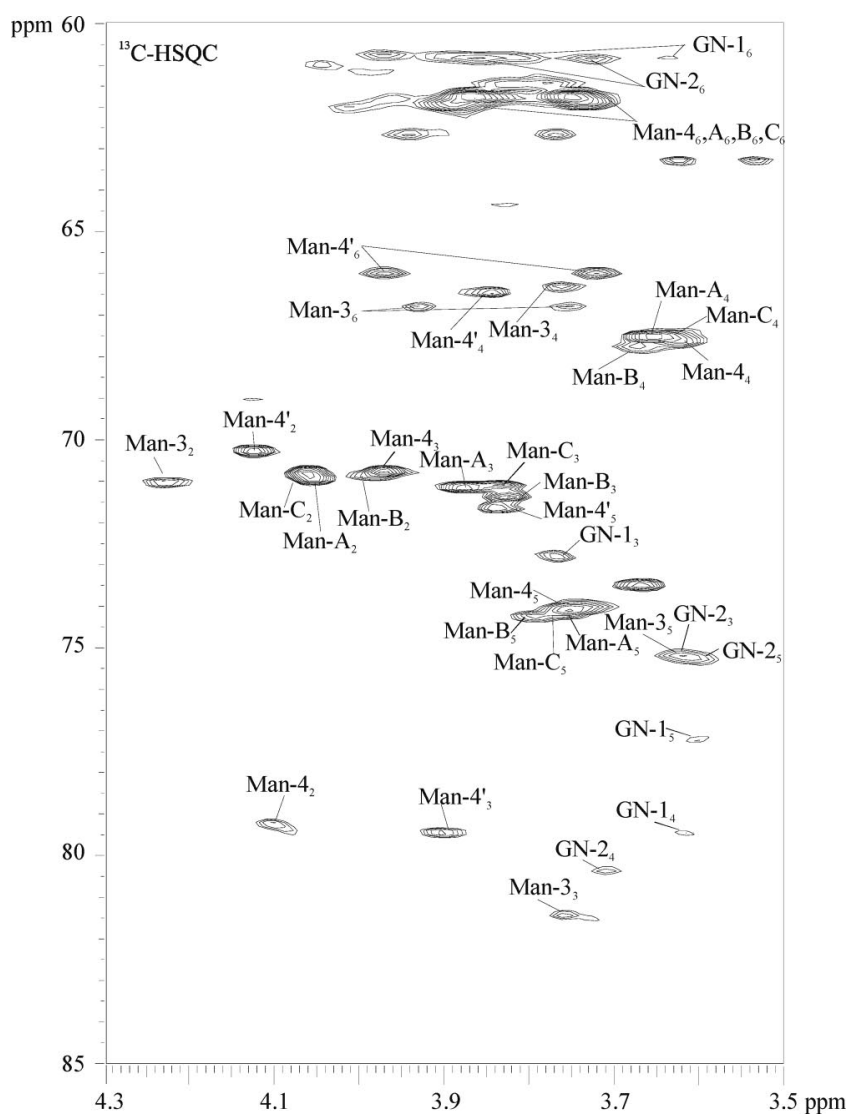

FIGURE 6: 700-MHz ${ }^{13} \mathrm{C}-{ }^{1} \mathrm{H}$ HSQC spectrum (nonanomeric region) of the glycan at Asn-34 in RNase B, recorded at $308 \mathrm{~K}$ in $\mathrm{D}_{2} \mathrm{O}$. Man, mannose; GN, GlcNAc.

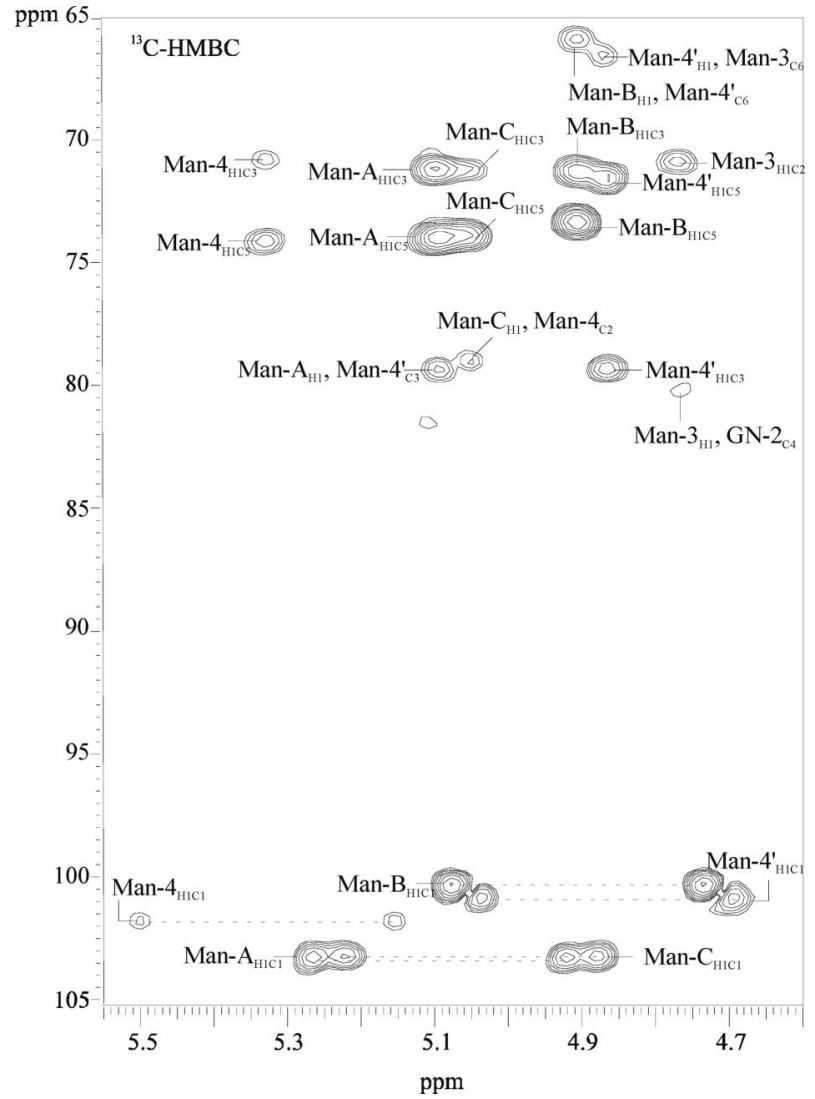

FigURE 7: 500-MHz ${ }^{13} \mathrm{C}-{ }^{1} \mathrm{H}$ HMBC spectrum (anomeric region) of the glycan at Asn-34 in RNase B, recorded at $308 \mathrm{~K}$ in $\mathrm{D}_{2} \mathrm{O}$. Man, mannose; GN, GlcNAc.

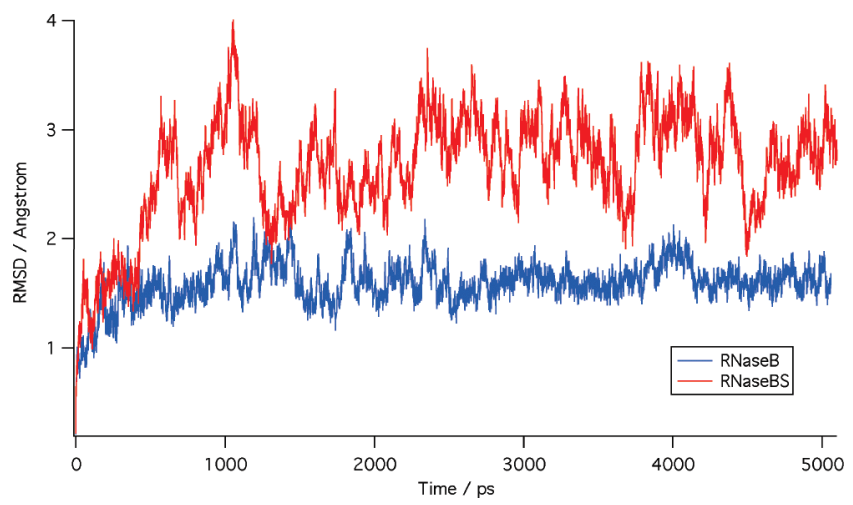

FIGURE 8: rmsd analysis of the protein backbone atoms for RNase B (blue) and RNase BS (red).

Man-C H-2,3,4,5. On the guidance of literature data (24), Man- $\mathrm{C}$ H-6a and H-6b could be assigned in the ${ }^{13} \mathrm{C}-{ }^{1} \mathrm{H}$ HSQC spectrum (Figure 6) at $\delta 3.76 / 61.7$ and 3.88/61.7, respectively. The Man-A H-1 TOCSY track $(\delta 5.09)$ showed cross-peaks with Man-A H-2,3,4,5. Also, Man-A H-6a,6b, overlapping with Man-C H-6a,6b, were assigned on the guidance of literature data (24). The ${ }^{1} \mathrm{H}$ signals of Man-B ( $\mathrm{H}-1$ track at $\delta 4.90)$ were assigned in the same way that was used for Man-A. The Man- $4^{\prime}$ H-1 TOCSY track $(\delta 4.87)$ showed cross-peaks with Man-4' H-2,3,4,5. Interresidual connectivities between Man-B H-1 and Man-4' H-6a,6b in the NOESY spectrum (mixing time of $80 \mathrm{~ms}$ ) at $\delta 4.90 /$ 3.75 and 3.97 (Figure 5a) and between Man-B H-1 and Man$4^{\prime} \mathrm{C}-6$ in the ${ }^{13} \mathrm{C}-{ }^{1} \mathrm{H}$ HMBC spectrum at $\delta 4.90 / 66.0$ (Figure 7) allowed the assignment of Man-4' H-6a,6b. Compared to the C-6 resonances of Man-A, $-\mathbf{B}$, and $-\mathbf{C}$, the Man-4' C-6 
(a)

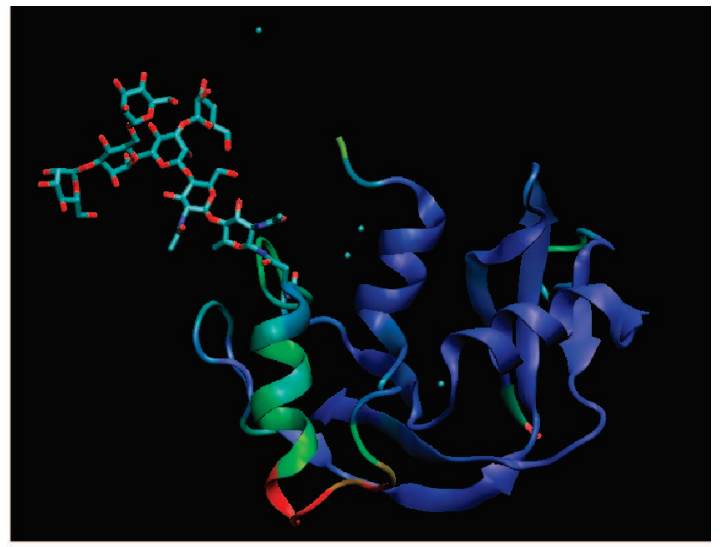

(b)

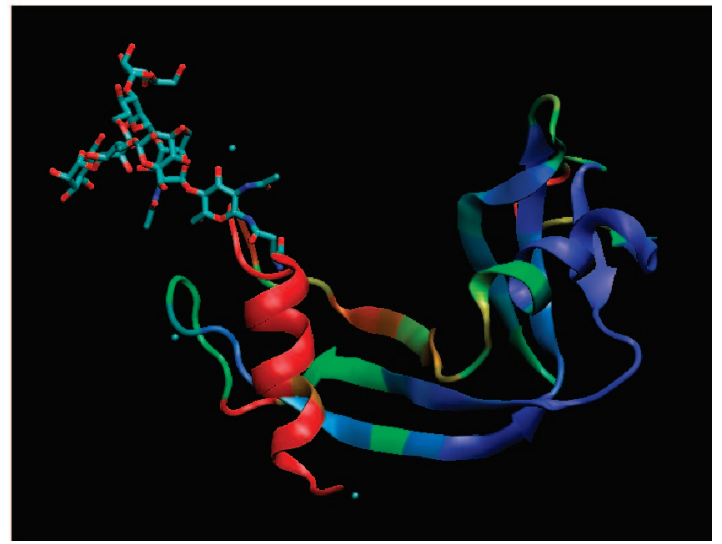

FIGURE 9: rmsd analysis per residue as a measure of flexibility occurring in RNase B (a) and RNase BS (b). Dark blue means not flexible (rmsd $<1 \AA$ ); intensive red means flexible ( $\mathrm{rmsd}>3 \AA$ ), and green means $1 \AA<$ rmsd $<3 \AA$.

resonance is shifted downfield by $\sim 4 \mathrm{ppm}$, due to the substitution of Man-4' O-6 by Man-B. The Man-4' C-4 signal is traced via Man-4' $\mathrm{H}-2$ in the ${ }^{13} \mathrm{C}-{ }^{1} \mathrm{H}$ HMBC analysis (data not shown), which made it possible to confirm Man-4' $\mathrm{H}-4$ in the ${ }^{13} \mathrm{C}-{ }^{1} \mathrm{H}$ HSQC spectrum (Figure 6). The TOCSY spectra show Man-4 H-2 at $\delta 4.11$ on the Man-4 H-1 track ( $\delta$ 5.33). Intraresidual connectivities between Man-4 H-1 and Man-4 C-3,5 were observed in the ${ }^{13} \mathrm{C}-{ }^{1} \mathrm{H}$ HMBC spectrum, thereby allowing the assignment of Man-4 H-3,5 in the ${ }^{13} \mathrm{C}-{ }^{1} \mathrm{H}$ HSQC spectrum. Man-4 H-4 and H-6a,6b, overlapping with Man-A, -B, and -C H-4 and H-6a,6b, respectively, were assigned on the guidance of literature data (24). A weak cross-peak at $\delta 4.77 / 4.23$ in the TOCSY spectrum allowed the assignment of Man-3 H-2 (data not shown). The assignments of the other Man-3 signals were completely deduced from the other NMR measurements. The ${ }^{13} \mathrm{C}-{ }^{1} \mathrm{H}$ HMBC spectrum showed the interresidual connectivities between Man-3 H-1 and C-2 ( $\delta$ 4.77/71.0) (Figure 7) and between Man-3 H-2 and C-3,4 ( $\delta$ 4.23/81.4 and 66.4) (data not shown). Man-3 H-6a,6b could be assigned via interresidual connectivities observed in the NOESY and ${ }^{13} \mathrm{C}-{ }^{1} \mathrm{H}$ HMBC spectra for Man-4' H-1/Man-3 H-6a,6b ( $\delta$ 4.87/3.77 and 3.94) and Man-4' H-1/Man-3 C-6 ( $\delta$ 4.87/66.8), respectively. Additional NMR data were obtained from the ${ }^{13} \mathrm{C}-{ }^{1} \mathrm{H}$ HSQC spectrum (Figure 6). For the assignment of the various NMR signals of GlcNAc-1 and GlcNAc-2 in the ${ }^{13} \mathrm{C}-{ }^{1} \mathrm{H}$ HSQC spectrum (Figures 4a and 6), use was made of the reported ${ }^{13} \mathrm{C}$ NMR data of the glycopeptide $\mathrm{Man}_{2} \mathrm{GlcNAc}_{2}$ Asn (compound IV in ref 26) and of other reference data $(24,25)$. It should be noted that the GlcNAc-1 H-1/C-1 signals $(\delta 5.10 / 79.0)$ are found at positions quite different from those of the GlcNAc-2 H-1/C-1 signals ( $\delta$ 4.60/101.2), illustrating the different influences of glycosidic nitrogen and oxygen. GlcNAc-2 H-4 $(\delta$ 3.72) was assigned according to the interresidual connections in the NOESY (Man-3 H-1, $\delta$ 4.77) (Figure 5a) and ${ }^{13} \mathrm{C}-{ }^{1} \mathrm{H}$ HMBC (Man-3 H-1/GlcNAc-2 $\mathrm{C}-4, \delta$ 4.77/80.3) (Figure 7) spectra. The assignment of GlcNAc-1 H-3 followed from intraresidual connectivity $\mathrm{H}-1 /$ $\mathrm{H}-3$ in the NOESY spectrum $(\delta 5.10 / 3.77)$. A long-range NOESY cross-peak was observed between GlcNAc-1 H-6b and Ser-32 $\mathrm{C}_{\alpha} \mathrm{H}$ of RNase B $(\delta 3.81 / 4.26)$.

The various ${ }^{1} \mathrm{H}$ and ${ }^{13} \mathrm{C}$ signals of the $N$-glycan at Asn-34 in RNase BS and RNase $\mathrm{B}^{\mathrm{cm}}$ were assigned by comparison with the RNase B data presented above (Table 2). Most values are fairly constant, except for GlcNAc-1 H-1 in RNase BS and RNase $\mathrm{B}^{\mathrm{cm}}$ and GlcNAc-1 H-5 in RNase $\mathrm{B}^{\mathrm{cm}}$. In the anomeric region of the ${ }^{13} \mathrm{C}-{ }^{1} \mathrm{H}$ HSQC spectra of RNase BS (Figure 4b) and RNase $\mathrm{B}^{\mathrm{cm}}$, the GlcNAc-1 H-1 resonances are found at upfield positions (0.09 ppm) when compared to RNase B (Figure 4a). As no NOESY cross-peaks were observed between the protein and the carbohydrate moieties in RNase BS and RNase $\mathrm{B}^{\mathrm{cm}}$, assignments of the amino acids in the protein parts were not made.

Molecular Dynamics Simulations of RNase B and RNase

\section{(a) RNase BS}
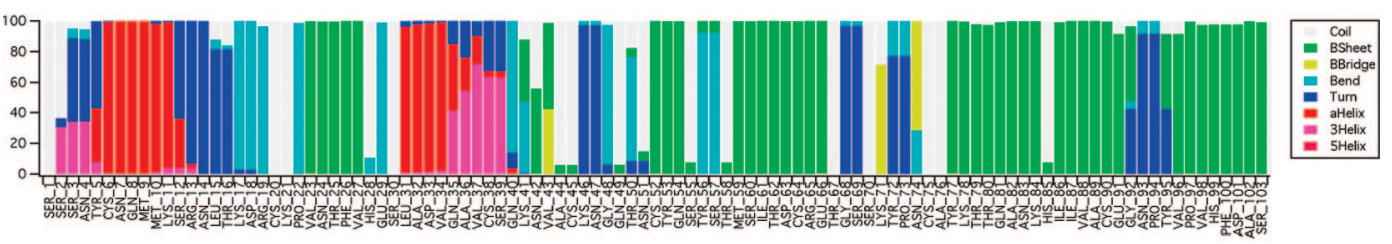

\section{(b) RNase B}
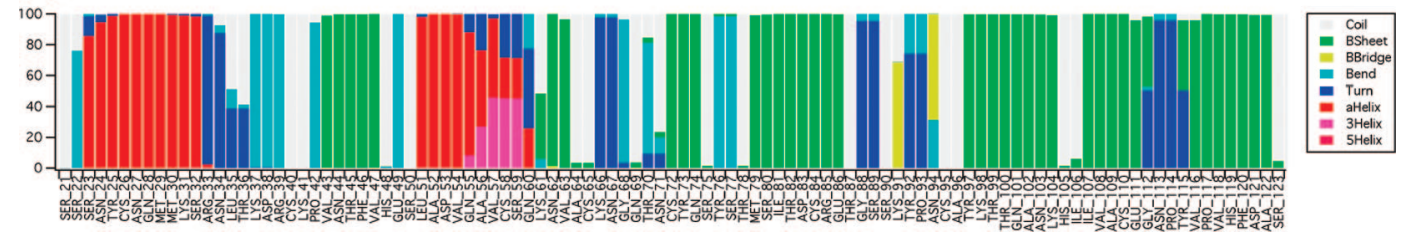

FIGURE 10: Analysis of the stability of secondary structure motifs during the MD simulation using DSSP in RNase BS (a) and RNase B (b). The figure shows the relative percentage of a residue being part of a secondary structure motif. The whole trajectory is analyzed; e.g., Ser-22 is in approximately $75 \%$ of the snapshots in a bend and in $25 \%$ of the snapshots in a coil (for RNase B). 

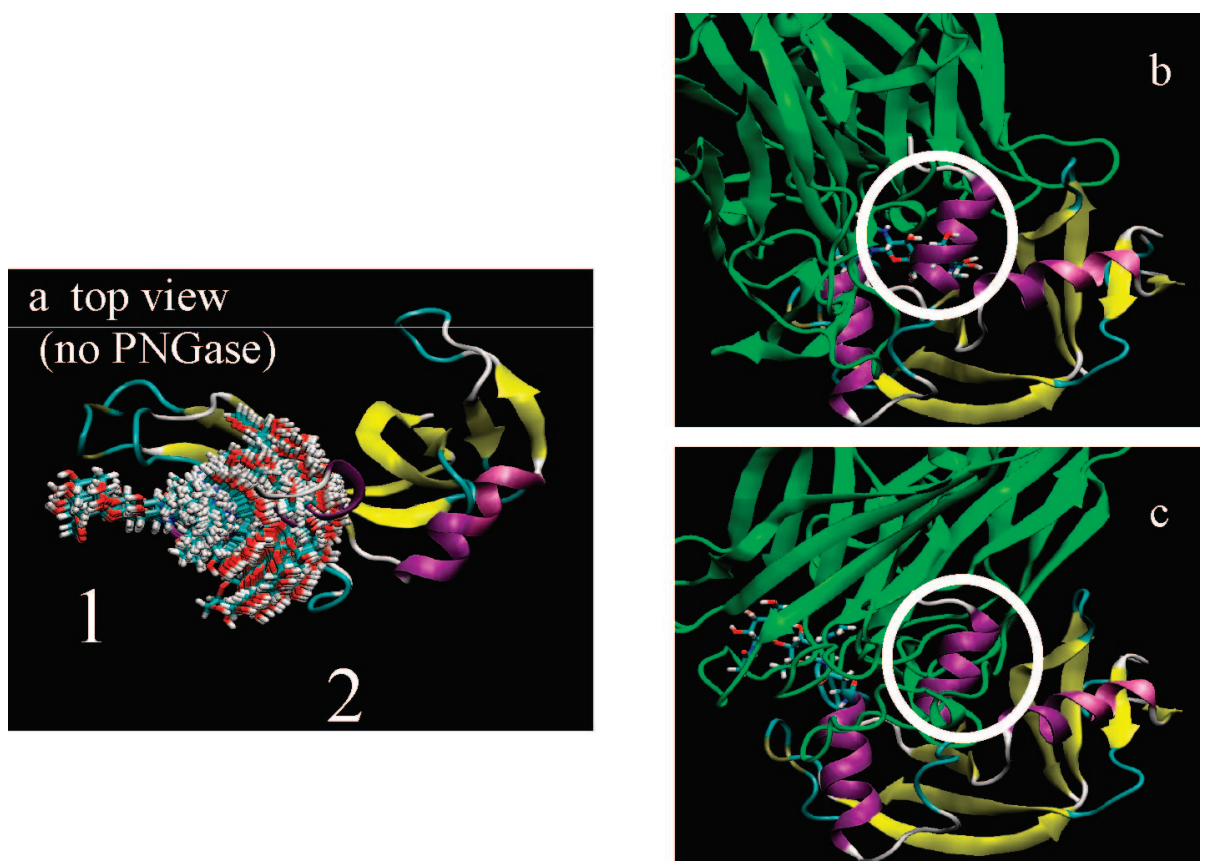

FIGURE 11: Possible orientations of the GlcNAc $(\beta 1-4) \operatorname{GlcNAc}(\beta 1-\mathrm{N})$ element at Asn-34 in the RNase B-PNGase F complex. Orientations with fewer than 90 overlapping atoms are displayed. Two orientational families/clusters are observed. (a) In situation 1, the glycan is pointing outside RNase B, whereas in situation 2, the glycan is pointing toward the inner part of RNase B. PNGase F is not displayed for clarity. (b) Representation of the complex with a glycan of orientation 2. (c) Representation of the complex with a glycan of orientation $\mathbf{1 .}$ Overlapping regions are circled.

$B S$ in Solvent. MD simulations were carried out on RNase $\mathrm{B}$ and RNase BS in water as described in Experimental Procedures. The backbone atoms of residues 40-120 were superimposed, and rmsd values of protein backbone atoms were calculated to estimate and compare the stability/ flexibility of the two glycoproteins. The overall rmsd analysis of the protein backbone atoms (Figure 8) revealed that during the MD the RNase BS structure moves significantly farther from the starting structure than the RNase B structure. The rmsd value for RNase BS is approximately twice as high ( $\sim 3.0 \AA)$ and shows strong fluctuations even after 5 ns. A similar result was found for RNase A (27). Our results are a first indication that removal of the $\mathrm{S}$ peptide (amino acids 1-20) introduces instability into the glycoprotein structure also. Analyzing "rmsd values per residue" is a good strategy for locating regions of high flexibility within the protein. Comparing the analyses for RNase B (Figure 9a) and RNase $\mathrm{BS}$ (Figure 9b) reveals that in RNase BS the regions showing higher flexibility are between amino acids 21 and 38, 64 and 70 , and 86 and 92 (residue numbering based on RNase B). The secondary structure (DSSP) analysis shows that regions where changes in secondary structure could be observed are limited mainly to residues $23-32$. Here, the $\alpha$-helix changes partly to a 3-helix or turn motif (Figure 10). The main effect that can be seen from the data is that removal of the first $\alpha$-helix (amino acids $1-20$ ) destabilizes the second $\alpha$-helix (amino acids 23-32) in its relative position and also in its fold, as revealed from the analysis of the secondary structure (Figure 10). This finding is not an artifact of superimposing residues 40-120 for the rmsd analysis: using all backbone atoms for superimposition gives the same result.

In both MD simulations, the glycosidic torsion angles $\varphi_{\mathrm{N}} /$ $\psi_{\mathrm{N}}$ fluctuate around a minimum at $\varphi_{\mathrm{N}} / \psi_{\mathrm{N}}=240 \pm 22^{\circ} / 180 \pm$ $12^{\circ}$, which is in good agreement with values derived from an extensive analysis of $\mathrm{N}$-glycosylation sites based on X-ray crystallographic data (28). The Asn-34 side chain torsion $\chi_{1}$ shows similar flexibility for RNase B and BS $\left(\chi_{1}=300 \pm\right.$ $\left.13^{\circ}\right)$. On the other hand, a clearly different behavior was found for $\chi_{2}$ : during the MD simulation of RNase B, mainly the $\mathrm{g}^{-}$ conformer is populated $\left(\chi_{2}=275 \pm 25^{\circ}\right)$, whereas in RNase $\mathrm{BS}$, the system spent a significant amount of time also in the $\mathrm{t}$
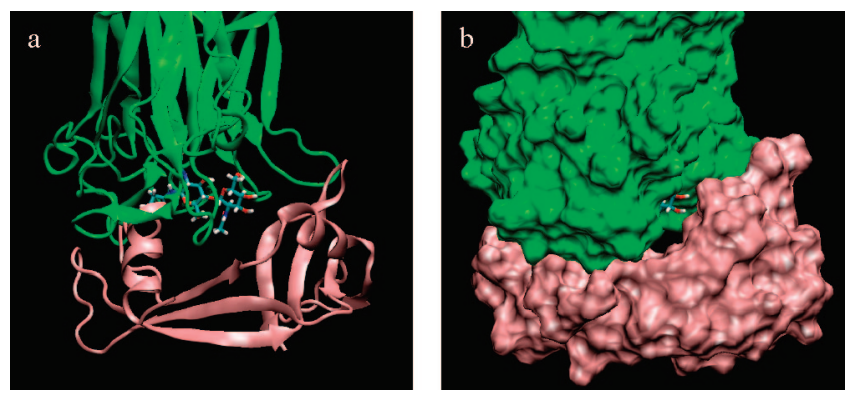

FIGURE 12: Representation of the RNase BS-PNGase F complex with a glycan of population 2: (a) display with ribbons and (b) display with surfaces.

Table 3: Amino Acid Overlaps in the RNase BS-PNGase F Complex in Orientations $\mathbf{1}$ and $\mathbf{2}^{a}$

\begin{tabular}{cccccc}
\hline orientation & RNase BS & PNGase F & orientation & RNase BS & PNGase F \\
\hline $\mathbf{1}$ & Met-29 & Ala-245 & $\mathbf{2}$ & Met-29 & Ile-193 \\
& Met-30 & Asn-243 & & Met-29 & Asn-288 \\
& Ser-32 & Tyr-85 & & Thr-36 & Asn-243 \\
& Ser-32 & Asn-243 & & Lys-37 & Tyr-85 \\
& Arg-33 & Asn-243 & & Lys-37 & Asn-243 \\
& Arg-33 & Trp-244 & & Lys-37 & Trp-244 \\
& Arg-33 & Arg-248 & & Lys-37 & Pro-253 \\
& Leu-35 & Trp-207 & & Asp-38 & Tyr-85 \\
& Asp-38 & Ile-193 & & Asp-38 & Gly-242 \\
& Arg-39 & Tyr-197 & & Arg-39 & Pro-241 \\
& Phe-46 & Pro-246 & & & \\
& Val-118 & Phe-209 & & \\
\hline
\end{tabular}

${ }^{a}$ In RNase BS, the amino acids are numbered from 21 to 124 . In PNGase F, the amino acids are numbered from 1 to 314 . 
Table 4: ${ }^{1} \mathrm{H}$ Chemical Shifts for the GlcNAc-1 Residues of RNase B, RNase $\mathrm{B}^{\mathrm{cm}}$, RNase BS, and Various Glycopeptides and Glycoproteins ${ }^{a}$

\begin{tabular}{ccccccc}
\hline compound $^{b}$ & H-1 & H-2 & H-3 & H-4 & H-5 & H-6a,6b \\
\hline a & 5.10 & 3.84 & 3.77 & 3.62 & 3.60 & $3.63,3.81$ \\
b & 5.01 & 3.81 & 3.77 & 3.63 & 3.50 & $3.63,3.76$ \\
c & 5.01 & 3.83 & 3.77 & 3.62 & 3.61 & $3.63,3.81$ \\
d & 5.01 & 3.82 & 3.68 & 3.46 & 3.59 & $\mathrm{nd}^{c}$ \\
e & 5.06 & 3.86 & 3.76 & 3.66 & $\mathrm{nd}^{c}$ & $\mathrm{nd}^{c}$ \\
f & 5.02 & 3.84 & 3.74 & 3.66 & $\mathrm{nd}^{c}$ & $\mathrm{nd}^{c}$ \\
g1 & 5.00 & 3.80 & 3.76 & 3.60 & 3.51 & $\mathrm{nd}^{c}$ \\
g2 & 5.28 & 3.90 & 3.65 & 3.71 & 3.25 & $\mathrm{nd}^{c}$
\end{tabular}

${ }^{a}{ }^{1} \mathrm{H}$ chemical shifts are referenced to acetone $(\delta 2.225)$ at $308 \mathrm{~K}$ unless indicated otherwise. ${ }^{b} \mathbf{a}$, native RNase B. b. unfolded RNase $\mathrm{B}^{\mathrm{cm}}$. $\mathbf{c}$, native RNase BS. d, human serum IgM-derived glycopeptide containing Asn-9, determined at $300 \mathrm{~K}$ (27). e, $\alpha$ hCG-derived glycopeptide containing Asn-52, determined at $298 \mathrm{~K}(28)$. f, $\alpha$ hCG-derived glycopeptide containing Asn-78, determined at $298 \mathrm{~K}$ (28). g1, Asn-52 in native ahCG (g), determined at $328 \mathrm{~K}(29)$. g2, Asn-78 in native $\alpha \mathrm{hCG}(\mathbf{g})$, determined at $328 \mathrm{~K}(29) .{ }^{c}$ Not determined.

conformer $\left(\chi_{2}=175 \pm 20^{\circ}\right)$. The $\mathrm{t}$ conformer is populated also in RNase B, but to a much lesser entent.

Molecular dynamics simulations of RNase B and RNase BS in explicit solvent covering a nanosecond time scale showed that removing the first 20 amino acids from RNase B makes the second $\alpha$-helix (amino acids 23-32) more flexible/instable. Other significant effects on the overall structure could not be observed during the simulation. Although there is some evidence that the linkage between GlcNAc-1 and Asn-34 is more flexible in RNase BS than in RNase B, it has to be noted that a simulation time of $5 \mathrm{~ns}$ is not long enough to justify final conclusions about the macroscopic stability of the protein fold or a statistically meaningful statement about flexibility differences in the glycan part. To observe larger conformational changes in the protein, an increase in the simulation time of at least 1 order of magnitude ( $\sim 50 \mathrm{~ns}$ ) would be required, which is beyond the scope of this study.

Building a Model of the RNase BS-PNGase F Complex. To build models for the RNase B-PNGase F and RNase BS-PNGase F complexes, the $N, N^{\prime}$-diacetylchitobiose contained in the crystal structure of PNGase F was superimposed on the $\operatorname{GlcNAc}(\beta 1-4) \operatorname{GlcNAc}(\beta 1-\mathrm{N})$ elements of RNase B and RNase BS. Subsequently, the most favorable orientation was obtained by a systematic search as described in Experimental Procedures. The minimum number of (heavy) atom overlaps was 58 for RNase B and 19 for RNase BS complexed with the PNGase F crystal structure. In general, two orientations
(1 and 2) of the disaccharide result in a small number of overlapping atoms (Figure 11a). In the case of RNase B, both orientations still result in severe sterical clashes with the $\alpha$-helix formed by amino acid residues 2-12 (Figure 11b,c). In the case of RNase BS, the problem with overlapping atoms is significantly reduced (Table 3 ). In the $\mathbf{1}$ form (carbohydrate oriented toward the solvent; $\chi_{1}=-120^{\circ}, \chi_{2}=-100^{\circ}$, and $\varphi_{\mathrm{N}}=$ $-120^{\circ}$ ), some minor overlapping occurs with the $\alpha$-helix formed by amino acid residues 25-33 (Table 3). The 2 form (carbohydrate points in the cleft of RNase; $\chi_{1}=80^{\circ}, \chi_{2}=$ $-140^{\circ}$, and $\varphi_{\mathrm{N}}=-60^{\circ}$ ) shows slightly less sterical conflict with respect to the protein atoms (Table 3).

Additionally, all snapshots sampled during the MD simulations to PNGase F have been docked by overlaying the GlcNAc 2 moiety (data not shown). The minimum number of clashes found for the MD simulations is higher than for the systematic search; therefore, it can be concluded that the optimum orientation of the glycan for attachment to PNGase $\mathrm{F}$ has not been sampled during the $5 \mathrm{~ns}$. However, on the basis of the statistical analysis of the generated complexes, a similar observation can be made: atom overlaps with the first 20 amino acids in RNase B constitute the major factor hindering complex formation.

\section{DISCUSSION}

As the enzymatic selectivity of PNGase F does not arise from the primary glycan structures, its resistance to RNase B suggests in this case a steric hindrance by the peptide backbone, a steric hindrance, that, in view of the results, does not occur in RNase $\mathrm{BS}$ and RNase $\mathrm{B}^{\mathrm{cm}}$. Direct NMR support for this suggestion could be inferred from a comparison of ${ }^{1} \mathrm{H}$ chemical shifts reported for Asn-linked GlcNAc-1 residues in native and nonnative/denatured environments. In Table 4, the ${ }^{1} \mathrm{H}$ NMR data of GlcNAc-1 of native RNase B (a), denatured RNase B ${ }^{\mathrm{cm}}(\mathbf{b})$, native RNase BS (c), an oligomannose-type $\operatorname{IgM} N$-glycopeptide (d), complex-type ahCG $N$-glycopeptides (e, Asn-52; f, Asn78), and native $\alpha$ hCG (g1, Asn-52; g2, Asn-78) are presented. A typical observation is that for RNase B (a) and $\alpha \mathrm{hCG}$ (g2) the GlcNAc-1 H-1 $\delta$ values are higher than those for the other compounds. Interestingly, only these two compounds are resistant to PNGase F digestion (glycopeptide $\mathbf{e}$ is excluded because of an N-terminal Asn-52 residue which makes it insensitive to PNGase F). In earlier studies of the threedimensional structure of $\alpha \mathrm{hCG}$ (g) in solution (31-34), we
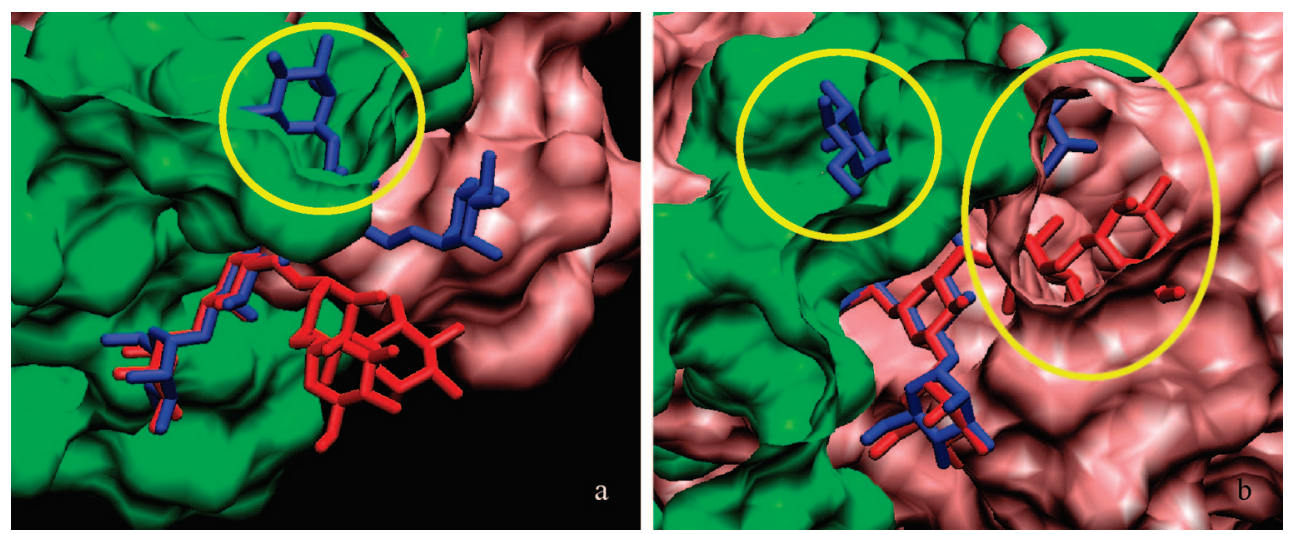

FIGURE 13: Attachment of $\mathrm{Man}_{5} \mathrm{GlcNAc}_{2}$ in orientations $\mathbf{1}$ (a) and $\mathbf{2}$ (b). The protein surface (green for PNGase F, pink for RNase BS) is clipped so that the carbohydrate residues located inside the protein can be seen [red for $\mathrm{Man}_{5} \mathrm{GlcNAc}_{2}(g g)$ and blue for $\mathrm{Man}_{5} \mathrm{GlcNAc}_{2}$ $(g t)]$. Carbohydrate residues located inside the protein are circled. 


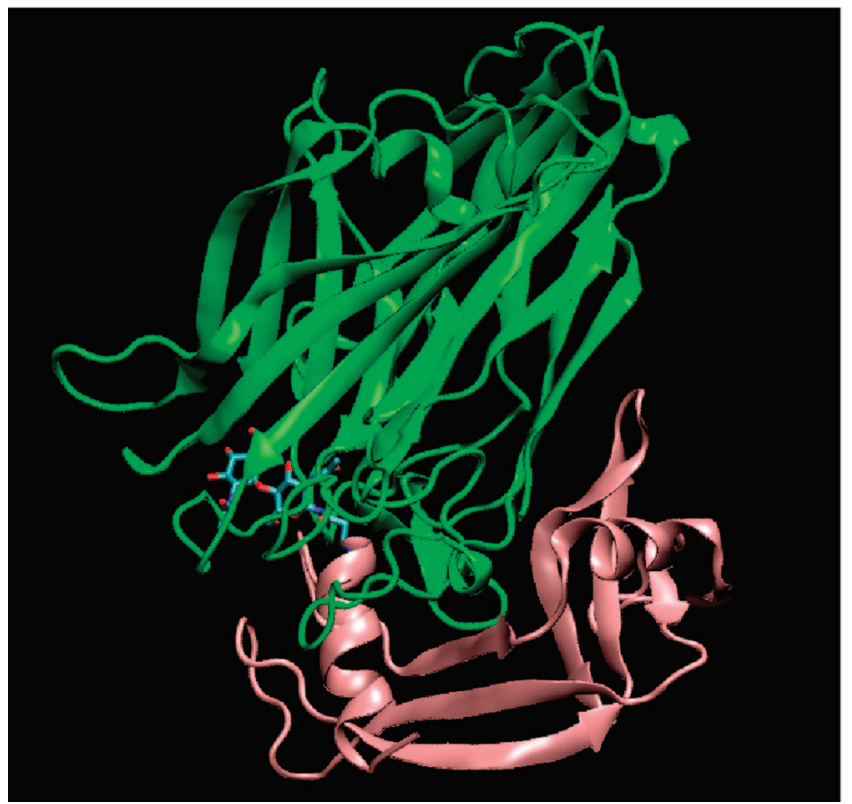

FIGURE 14: Representation of the RNase BS-PNGase F complex with a glycan of population $\mathbf{1}$ displayed with ribbons.

demonstrated that the inner core of the $N$-glycan moiety at $\alpha$ Asn-78 (g2) is capped into a hydrophobic patch (GlcNAc-1, $\mathrm{H}-1$ at $\delta 5.28$ ), whereas the inner core of the $N$-glycan at $\alpha$ Asn52 (g1) is freely exposed (GlcNAc-1, H-1 at $\delta$ 5.00) (31). Therefore, it is concluded in this study that the GlcNAc-1 H-1 value in RNase B $(\delta 5.10)$ reflects a restricted mobility due to the local conformation of the protein around Asn-34, which results in a resistance toward PNGase F. In contrast, the GlcNAc-1 H-1 values in RNase BS and RNase $\mathrm{B}^{\mathrm{cm}}(\delta$ 5.01), being close to the glycopeptide values, reflect a free exposure of the $N$-glycan to the solvent. An analogous interpretation has been reported for amino acid side chain NMR resonances in random coil polypeptides $(35,36)$. A long-range NOESY contact was observed in RNase B between GlcNAc-1 H-6b and Ser-32 $\mathrm{C}_{\alpha} \mathrm{H}$. This short distance was also observed in the MD simulations.

Comparison of the ${ }^{13} \mathrm{C}-{ }^{1} \mathrm{H}$ HSQC spectra of RNase $\mathrm{B}$, RNase BS, and RNase $\mathrm{B}^{\mathrm{cm}}$ showed that the line widths of the $\mathrm{H}-1$ resonances belonging to GlcNAc-1, GlcNAc-2, and Man-3 are broader in RNase B (44, 36, and $36 \mathrm{~Hz}$, respectively) than in RNase BS and RNase $B^{\mathrm{cm}}$ (values of $\sim 30 \mathrm{~Hz}$ ). Such a difference was not observed for the remaining Man residues. It illustrates that in RNase B the mobility of the inner trisaccharide residues is much more restricted than in RNase $\mathrm{BS}$ and RNase $\mathrm{B}^{\mathrm{cm}}$. This finding indicates that removal of the $S$ peptide (amino acids 1-20) in RNase B, yielding RNase BS, induces an increase in the mobility of GlcNAc-1, GlcNAc-2, and Man-3 at Asn-34.

Results derived from the systematic search in the molecular modeling study revealed that no sterically possible orientation exists for RNase $B$ in which PNGase F can access the GlcNAc $(\beta 1-\mathrm{N})$ Asn linkage to cleave the amide bond. The $\alpha$-helix formed by amino acid residues $2-12$, which has been shown to be not very flexible in the MD simulations, is causing severe sterical overlap in all possible orientations of the attached carbohydrate. In contrast, in RNase BS, two orientations in which the PNGase F probably can access the $\operatorname{GlcNAc}(\beta 1-\mathrm{N})$ Asn linkage exist. While the $\mathbf{2}$ form has less steric conflict when using the rigid crystal coordinates for the two proteins in the systematic search, it might be questioned whether this solution is a realistic one for the following reason: when the full glycan $\left(\mathrm{Man}_{5-9} \mathrm{GlcNAc}_{2}\right)$ is present, the $(1-6)$ branch of the carbohydrate overlaps with the opposite part of RNase BS (Figure 13). Since the overlap occurs in a region where the two surfaces of the protein come close to each other, it is not very likely that a full $(1-6)$ branch can be accommodated by an induced fit. Therefore, orientation 2 can probably be ruled out.

In summary, the model shown in Figure 14 is an acceptable initial/preliminary model for the complex between RNase BS and PNGase F. The limited number of sterical conflicts with the $\alpha$-helix formed by amino acid residues 25-33 based on the rigid model is expected to be resolved when going to a flexible model. The MD simulations have shown that this part of the protein shows significant flexibility in RNase BS. On the basis of this model, the experimental finding that PNGase $\mathrm{F}$ is active on RNase BS but not on RNase B can be explained well.

\section{ACKNOWLEDGMENT}

We acknowledge Devashish Das and Dr. Tammo Diercks for their assistance in the NMR measurements and analysis.

\section{REFERENCES}

1. Nogués, M. V., Vilanova, M., and Cuchillo, C. M. (1995) Bovine pancreatic ribonuclease A as a model of an enzyme with multiple substrate binding sites. Biochim. Biophys. Acta 1253, 16-24.

2. Yajima, H., and Fujii, N. (1981) Totally synthetic crystalline ribonuclease A. Biopolymers 20, 1859-1867.

3. Howlin, B., Moss, D. S., and Harris, G. W. (1989) Segmented anisotropic refinement of bovine ribonuclease A by the application of the rigid-body TLS model. Acta Crystallogr. A45, 851-861.

4. Rico, M., Bruix, M., Santoro, J., González, C., Neira, J. L., Nieto, J. L., and Herranz, J. (1989) Sequential ${ }^{1} \mathrm{H}-\mathrm{NMR}$ assignment and solution structure of bovine pancreatic ribonuclease A. Eur. J. Biochem. 183, 623-638.

5. Robertson, A. D., Purisima, E. O., Eastman, M. A., and Scheraga, H. A. (1989) Proton NMR assignments and regular backbone structure of bovine pancreatic ribonuclease $\mathrm{A}$ in aqueous solution. Biochemistry 28, 5930-5938.

6. Santoro, J., González, C., Bruix, M., Neira, J. L., Nieto, J. L., Herranz, J., and Rico, M. (1993) High-resolution three-dimensional structure of ribonuclease $\mathrm{A}$ in solution by nuclear magnetic resonance spectroscopy. J. Mol. Biol. 229, 722-734.

7. Arnold, U., and Ulbrich-Hofman, R. (1997) Kinetic and thermodynamic thermal stabilities of ribonuclease A and ribonuclease B. Biochemistry 36, 2166-2172.

8. Richards, F. M., and Vithayathil, P. J. (1959) The preparation of subtilisin-modified ribonuclease and the separation of the peptide and protein components. J. Biol. Chem. 234, 1459-1465.

9. Plummer, T. H., Jr., Elder, J. H., Alexander, S., Phelan, A. W., and Tarentino, A. L. (1984) Demonstration of peptide:N-glycosidase $\mathrm{F}$ activity in endo- $\beta$ - $N$-acetylglucosaminidase $\mathrm{F}$ preparations. J. Biol. Chem. 259, 10700-10704.

10. Tarentino, A. L., Gómez, C. M., and Plummer, T. H., Jr. (1985) Deglycosylation of asparagine-linked glycans by peptide:N-glycosidase F. Biochemistry 24, 4665-4671.

11. Hirani, S., Bernasconi, R. J., and Rasmussen, J. R. (1987) Use of $\mathrm{N}$-glycanase to release asparagine-linked oligosaccharides for structural analysis. Anal. Biochem. 162, 485-492.

12. Trombetta, E. S., and Helenius, A. (2000) Conformational requirements for glycoprotein reglucosylation in the endoplasmic reticulum. J. Cell Biol. 148, 1123-1129.

13. Lustbader, J., Birken, S., Pollak, S., Levinson, L., Berstine, E., Hsiung, N., and Cornfield, R. (1987) Characterization of the expression products of recombinant human choriogonadotropin and subunits. J. Biol. Chem. 262, 14204-14212.

14. Berman, H. M., Westbrook, J., Feng, Z., Gilliland, G., Bhat, T. N., Weissig, H., Shindyalov, I. N., and Bourne, P. E. (2000) The Protein Data Bank. Nucleic Acids Res. 28, 235-242. 
15. Case, D. A., Cheatham, T. E., III, Darden, T., Gohlke, H., Luo, R., Merz, K. M., Jr., Onufriev, A., Simmerling, C., Wang, B., and Woods, R. J. (2005) The Amber biomolecular simulation programs. J. Comput. Chem. 26, 1668-1688.

16. Frank, M. (2005) Conformational Analysis Tools (CAT), http:// www.md-simulations.de/CAT/.

17. Woods, R. J., Dwek, R. A., Edge, C. J., and Fraser-Reid, B. (1995) Molecular mechanical and molecular dynamical simulations of glycoproteins and oligosaccharides. 1. Glycam-93 parameter development. J. Phys. Chem. 99, 3832-3846.

18. Berendsen, H. J. C., Postma, J. P. M., van Gunsteren, W. F., DiNola, A., and Haak, J. R. (1984) Molecular dynamics with coupling to an external bath. J. Chem. Phys. 81, 3684-3690.

19. Humphrey, W., Dalke, A., and Schulten, K. (1996) VMD: Visual molecular dynamics. J. Mol. Graphics 14, 33-38.

20. Kabsch, W., and Sander, C. (1983) How good are predictions of protein secondary structure. FEBS Lett. 155, 179-182.

21. Woods, R. J., Pathiaseril, A., Wormald, M. R., Edge, C. J., and Dwek, R. A. (1998) The high degree of internal flexibility observed for an oligomannose oligosaccharide does not alter the overall topology of the molecule. Eur. J. Biochem. 258, 372-386.

22. Gotte, G., Libonati, M., and Laurents, D. V. (2003) Glycosylation and specific deamidation of ribonuclease $\mathrm{B}$ affect the formation of three-dimensional domain-swapped oligomers. J. Biol. Chem. 278, 46241-46251.

23. Gutiérrez-Gallego, R., Haseley, S. R., van Miegem, V. F. L., Vliegenthart, J. F. G., and Kamerling, J. P. (2004) Identification of carbohydrates binding to lectins by using surface plasmon resonance in combination with HPLC profiling. Glycobiology 14, 373-386.

24. Wyss, D. F., Choi, J. S., and Wagner, G. (1995) Composition and sequence specific resonance assignments of the heterogeneous $\mathrm{N}$-linked glycan in the $13.6 \mathrm{kDa}$ adhesion domain of human CD2 as determined by NMR on the intact glycoprotein. Biochemistry $34,1622-1634$

25. González, L., Bruix, M., Díaz-Mauriño, T., Feizi, T., Rico, M., Solis, D., and Jiménez-Barbero, J. (2000) Conformational studies of the Man oligosaccharide on native ribonuclease $\mathrm{B}$ and on the reduced and denatured protein. Arch. Biochem. Biophys. 383, 17-27.

26. Dijkstra, B. W., Vliegenthart, J. F. G., Strecker, G., and Montreuil, J. (1983) Natural-abundance ${ }^{13}$ C-NMR spectroscopy of two glycoasparagines derived from the core of $\mathrm{N}$-glycosidic carbohydrate chains. Eur. J. Biochem. 130,111-115.
27. Cotesta, S., Tavernelli, I., and Di Iorio, E. E. (2003) Dynamics of RNase-A and S-protein: A molecular dynamics simulation of the transition toward a folding intermediate. Biophys. J. 85, 2633-2640.

28. Petrescu, A. J., Milac, A. L., Petrescu, S. M., Dwek, R. A., and Wormald, M. R. (2004) Statistical analysis of the protein environment of N-glycosylation sites: Implications for occupancy, structure, and folding. Glycobiology 14, 103-114.

29. Wormald, M. R., Wooten, E. W., Bazzo, R., Edge, C. J., Feinstein, A., Rademacher, T. W., and Dwek, R. A. (1991) The conformational effects of $\mathrm{N}$-glycosylation on the tailpiece from serum IgM. Eur. J. Biochem. 198, 131-139.

30. Weisshaar, G., Hiyama, J., and Renwick, A. G. C. (1991) Sitespecific N-glycosylation of human chorionic gonadotrophin, structural analysis of glycopeptides by one- and two-dimensional ${ }^{1} \mathrm{H}-$ NMR spectroscopy. Glycobiology 1, 393-404.

31. van Zuylen, C. W. E. M., de Beer, T., Rademaker, G. J., Haverkamp, J., Thomas-Oates, J. E., Hård, K., Kamerling, J. P., and Vliegenthart, J. F. G. (1995) Site-specific and complete enzymic deglycosylation of the native human chorionic gonadotropin $\alpha$-subunit. Eur. J. Biochem. 231, 754-760.

32. de Beer, T., van Zuylen, C. W. E. M., Leeflang, B. R., Hård, K., Boelens, R., Kaptein, R., Kamerling, J. P., and Vliegenthart, J. F. G. (1996) NMR studies of the free $\alpha$-subunit of human chorionic gonadotropin. Structural influences of $\mathrm{N}$-glycosylation and the $\beta$-subunit on the conformation of the $\alpha$-subunit. Eur. J. Biochem. 241, 229-242.

33. Erbel, P. J. A., Karimi-Nejad, Y., de Beer, T., Boelens, R., Kamerling, J. P., and Vliegenthart, J. F. G. (1999) Solution structure of the $\alpha$-subunit of human chorionic gonadotropin. Eur. J. Biochem. 260, 490-498.

34. Erbel, P. J. A., Karimi-Nejad, Y., van Kuik, J. A., Boelens, R., Kamerling, J. P., and Vliegenthart, J. F. G. (2000) Effects of the $\mathrm{N}$-linked glycans on the 3D structure of the free $\alpha$-subunit of human chorionic gonadotropin. Biochemistry 39, 6012-6021.

35. McDonald, C. C., and Phillips, W. D. (1967) Manifestations of the tertiary structures of proteins in high-frequency nuclear magnetic resonance. J. Am. Chem. Soc. 89, 6332-6341.

36. Wüthrich, K. (1986) NMR of amino acid residues and mononucleotides, in NMR of proteins and nucleic acids, pp 13-25, John Wiley \& Sons Ltd., London, U.K.

37. Lütteke, T., Frank, M., and von der Lieth, C.-W. (2005) Carbohydrate Structure Suite (CSS): Analysis of carbohydrate 3D structures derived from the PBD. Nucleic Acids Res. 33, D242-D246.

BI7012504 